\title{
COMMUNITY BASED URBAN AREA CONSERVATION LESSONS FROM PAKISTAN
}

\author{
Shabnam Nigar Mumtaz*
}

\begin{abstract}
Pakistan has a treasure of historic cores as part of various cities that date back to Pre-Mughal, Mughal and Post Mughal periods. Even those cities that were developed during the 19th century British rule have areas that are valuable as representative of a shared heritage with colonies of Britain. Since many historic cores have become part of the cities, these historic cores are seriously threatened.

Unesco World Heritage List includes many major historical monuments and sites of Pakistan but it is yet to list any historical town in Pakistan .The local legislation also does not list any historical town. In spite of their value, most historical areas are deteriorated and many parts of this significant heritage have been lost over the years.

Community based conservation promotes the idea that the key to success of long term conservation lies in community engagement, bringing the benefits of historical conservation to the local community. However, although community based conservation is practiced commonly world wide, it is not always successful.
\end{abstract}

This paper tries to answer the following questions: 1. Is community based conservation an effective tool in Pakistan for conservation of urban areas?

2. What are the factors that contribute to the success or failure of such conservation exercises?

3. What part does a project design and local community character play in the success or failure of an urban conservation project?

A multi sited case study method has been used for this paper to research and analyse conservation projects having similarities and differences related to heritage conservation. Each site has been analysed for its unique local context and each project has been reviewed for the different project designs which speak about the multi layered challenges of heritage conservation.

The three cases presented here offer valuable lessons for the design and implementation of area conservation programs in Pakistan. One lesson is the need to put all values embedded in urban heritage into play, as they are the drivers that mobilize a diverse set of stakeholders. These values include cultural and social justice, historic, artistic, educational and economic factors that can mobilize community, government, elite, philanthropist and entrepreneurs. The premise of analysis here is that more the variety of values, the more sustainable the conservation.

The methodology used is literature review from secondary sources i.e. books, articles, academic papers and discussions with colleagues. The conclusion points towards the fact that in Pakistan community based conservation may not be the only solution to area conservation because only few groups can value it, like academia, groups from civil society and some government departments. Communities at large need more motivation and awareness to become the major participant of urban area conservation exercises. The role of elite and private sector is also very insignificant. Any external agency can help only in advisory and financial capacity, but means to generate funds locally should be there.

Keywords: Urban area conservation, community, Pakistan, heritage, historic cores

\section{INTRODUCTION}

The status of urban area conservation is described by an academic conservationist Prof. Dr. Anila Naeem form the Department of Architecture and Planning, NED University of Engineering and Technology in 2009 as follows:

\footnotetext{
* Shabnam Nigar Mumtaz, Assistant Professor, Department of Architecture and Planning, NED University of Engineering and Technology, Karachi. Email correspondence: shabnamnigar@yahoo.com
} 


\begin{abstract}
"In Pakistan urban area conservation is not an established professional field and designation of historic centers is altogether a very new idea. Thus, conserving urban heritage areas may take many shapes and meanings and conservation of urban areas is more complex than conservation of individual buildings or archaeological remains".
\end{abstract}

The urban in Pakistan is defined as places with municipal corporation, town committee or cantonment (Demographic Yearbook, 2005). Pakistan has experienced large population increase in urban areas over the past six decades. The population growth rate is averaged around $2.5 \%$ per year for rural areas and around 3.5\% per year for urban areas. It is speculated that by the year 2030, the urban population will become $50 \%$ of the total population. With such rate of growth in the cities of Pakistan sustainable development can only be brought by creating the balance between the new development and redevelopment of existing areas. Heritage conservation is an essential part of this sustainable redevelopment.

Pakistan has a wealth of historic cores as part of various cities that date back to Mughal and post Mughal periods. Even those cities that were developed during the $19^{\text {th }}$ century have areas that are of extreme value as representative of a shared heritage with Britain. Since many historic cores have become part of the city center or old town, the historic areas in these cores are gravely threatened. These areas require area conservation techniques to resolve their issues. There are three classifications of tangible heritage i.e. world heritage, namely national heritage, local heritage and urban historic cores. Urban area conservation can be part of any heritage classification.

\section{AIMS AND OBJECTIVES}

This paper aims to review current practices of community based area conservation in Pakistan for the possibility of expanding / building upon new conservation approaches. The idea here is to base the future strategies on experience by analyzing the issues at hand that all stake holders are facing and thinking of strategies that could benefit locals.

The specific objectives of this paper are as follows:

- To examine the overall effectiveness of community based conservation in Pakistan.

- The factors that might affect the success or failure of community based conservation.

- The part that the national context, project design and local community character plays in the success and failure of urban conservation project.

\section{METHODOLOGY}

This paper is divided into two parts. The first part is a summary of the literature reviewed about area conservation in an urban context and the second part is based on case studies.

The literature consulted is mostly from secondary source articles from journals, books, internet sources and newspaper clippings. A case study method has been chosen to get an idea of the problems involved in urban area conservation in Pakistan and its solutions. The case studies chosen from Pakistan are the City of Uch, the Walled City of Lahore and the Saidpure village conservation project. These cases have been taken because they involve area conservation strategies in an urban background.

\section{URBAN AREA CONSERVATION}

In 1964 the ICOMOS Venice Charter although emphasizing the cultural significance of individual monuments, extended the concept of the historic monument from not only a single architectural work to an urban setting in which is found the evidence of a particular civilization (International Council of Monuments and Sites, 1964). In the European context, the Amsterdam Declaration built on this idea by stressing the need to develop integrated conservation policies. It emphasized that protection policies should be devised to safeguard the traditional environment of historic towns and old quarters of cities, as well as towns and villages with traditional character, and to ensure the interaction of functions and the continuation of social and cultural diversity that characterizes such places.

The key issue identified in this respect was that integrated conservation of architectural heritage should be regarded as a fundamental component of local and regional planning, that budgetary policies allocating funds for new development and construction should be redirected more evenly between rehabilitation and for development of new building.

Urban Area Conservation in the contemporary World

Most new development and redevelopment projects in cities impact upon space the existing fabric and the socio-economic character of a place. Due to the change in the socio economics of cites, redevelopment of urban areas has increased over the years and has endangered the existing urban heritage. The planning for urban growth is done with the objective 
of raising the standard of living of the urban resident, in terms of changed social, cultural and environmental fabric. With the evolution of the concept of sustainability, planners are trying to create a balance between new and old development and protect urban heritage. The change in the socio economic conditions has also changed the aspirations and values regarding the common built future. The neo liberal paradigm has left the development of the cities in the hands of market economy without safeguarding against its externalities.

\section{Urban Area Conservation Policies in Pakistan}

In the year 2016 when trying to review the area based conservation approach in Pakistan, there were very few local examples to learn from.

There are many historic areas within the cities in Pakistan. Most of them are at the centre or the old town areas. Conserving urban heritage areas may take many shapes and many meanings. Conservation of living areas is more complex than conservation of individual buildings or archaeological remains.

In the Pakistani context scholars as well as concerned citizens involved in urban planning and conservation, desire to protect their urban historical places, like their historic towns or historic cores of large cities. Pakistan has a number of cities like Karachi, Hyderabad, Lahore, Multan and many others with historic areas that need to be preserved. The national policies in Pakistan acknowledge many archaeological sites and monuments, giving them certain levels of protection, but historic towns and urban historic cores are largely ignored, thus subject to adverse transformations due to development pressures, mismanagement and exclusion from planning policies (Laiq and Soomro, 2011).

The few urban conservation cases that are seen in this direction are community based approaches. These are the conservation exercise in the city of Uch or Urban design exercise of Saidpur Village in Islamabad and Walled City renovation of Lahore.

In the present age of globalization, heritage area conservation is seen as the tool for culture led regeneration of cities for creating an image and identity of the city and to improve its economy. Globalization today values the diversity of cultures and cities, and promotes retention of historical urban cores. The policy of area conservation however, is not without critique. Prof Goodey, Emeritus Professor Brian Goodey, of Oxford Brooks Univeristy, talking on this issue in Karachi said that when the question of designating places is raised there is a kind of tension in this regard. Professionally when one starts to gather information about an urban area, one usually demarcates areas or regions with certain qualities to make them stand out from the rest, and many things happening in today's world militate against that psychoogically. Boundaries shift very rapidly and spatial understandings are shifting too so the question areses if one should really strive to get definitive lines around things, objects or spaces? Demarcating an urban area is one of the key features of conservation research and one has to question if putting a line around a space or region is an effective means of defining an inevitably evolving or transforming urban space, or defining the area through a rolling or spot program is a better option.

There were some commonalities in the projects that are selected from Pakistan which are outlined here:

1. The projects were funded by either external sources or by a combination of both external source and public agency.

2. The socio-economic and governance profile is low.

3. The awareness level on heritage conservation is also low.

\section{CASE STUDIES}

\section{Case Study 1: The City of Uch}

Built on the experience of Karimabad Area conservation Project within the rural setting, the Aga Khan Cultural Support Program desired to undertake a similar area based conservation exercise for another urban area. Historic Cities within the Agha Khan Cultural Support Program promote the conservation and reuse of buildings and public spaces in historic cities in the Muslim world. The villages and neighbourhoods around Baltit Fort, which were in danger of being deserted in favour of new construction, have been rehabilitated with the active participation of residents. The Aga Khan Trust for Culture, through its local company Aga Khan Cultural Service - Pakistan (AKCS-P), engaged in reviving pride and identity through interventions in cultural heritage that supported social, physical and institutional development. In the fifteen years of operation from 1992 to 2007, several key principles guided the revitalization efforts. The first principle was that restoration must lead to the infusion of new life into historic landmark buildings, which made them meaningful for the local communities and the users. The project intended to unite issues of public health, 
sanitation and environmental for upkeep of the city, which was the core issue of sustainable area conservation. The objective was to provide technical help to the municipal institutions and to help them build institutional capacity, planning frameworks and rationalize investments made by public sector on infrastructure and roads, while enhancing organizational and technical capacities (Khan, 1999).

The City of Uch, which is a small historic town in rural lower Punjab located at the meeting point of River Indus and River Sutlej was a once a large port city. Uch (present population 20,000) was a major regional capital in the past. In spite of its demotion to economic and political insignificance, Uch shares a great deal of cultural heritage with large historic cities like Multan and Lahore. Today's Uch represents social and economic inertia caused by long social neglect and low developmental priorities for such towns. Present day Uch comprises of two distinct historic centers-Uch Bukhari and Uch Gilani. Distributed over these two halves of the city are the total sixteen listed monuments. These monuments are protected under the Antiquities Act of 1976 and are under the care of the Department of Archaeology and Museums (Khan, 1999) (Figure 1).

According to Hasan (2010) the situation of Uch is related to migration of better educated citizens, the shift in control over land and local government by the influencial families and the proximity of economically better off towns on the main communications network close to Uch. Hasan (2010) is of the opinion that there is not much future for Uch and if Uch's monuments and status as an ancient town is to be rehabilitated it can be done by proper organization of religious festivals as they can become major touristic attractions.

The basic hiccup in the conservation of the Uch Monuments is the approach of the government towards conservation and urban planning "No matter how hard we try at putting

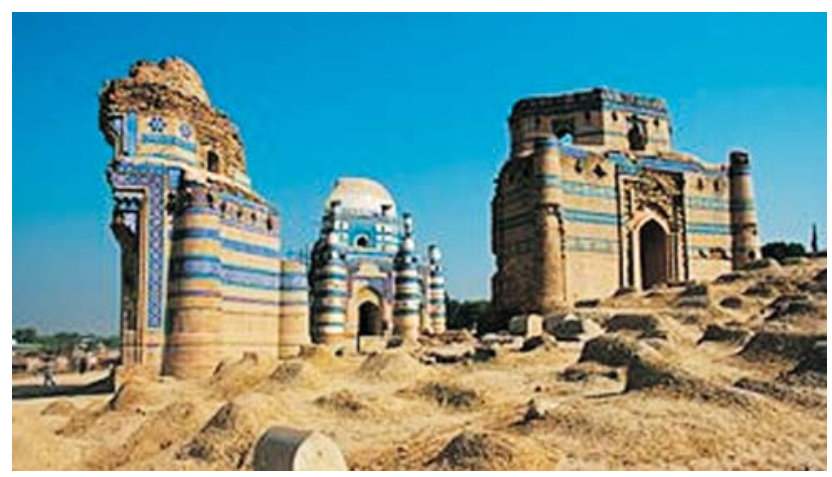

Figure-1: Tomb of Bibi Javindi. together a case for integrated conservation, the tendency on the part of government functionaries to pigeon-hole culture, heritage, conservation, development and urban development separately from one another which has been difficult to dislodge. It was only the backing of AKTC's Historic Cities Support Programme and of the World Monument Fund and the sheer visual and artistic impact of the exquisite 14 th and 15 th century glazed tile facing of the monuments in Uch that we were able to finally convince the Government of Pakistan to let us work in the city" (Khan, 1999:10).

General lack of awareness about heritage and its related management also results in poor urban conservation. The main issue was of waste water and solid waste disposal and institutional inadequacies. Thereby the first component of this program was sanitation. Community mobilization was relatively easy for sanitation program, the question of historic value, fabric and environmental rehabilitation was not incorporated in the beginning of the sanitation initiative as it was seen as a channel for future action. Community mobilization program had its inspiration from Orangi Pilot Project (OPP) in Karachi. Later on the heritage conservation of Uch was taken up by a Lahore based NGO, called Conservation and Rehabilitation Center which managed to get some funds for cultural heritage of Uch and conservation work has been carried out in this regard.

Professionals feel that the role of external agency is essential in an urban area conservation project but it has to be understood that the success of OPP in Karachi is based on its permanency and trust factor. Same is the case for Aga Khan Trust for Culture in Karimabad. Similar results cannot be achieved by a short intervention of any external agency. Their capacity for increasing the ability of municipality on technical issues may help in that direction, evident in both the case studies of Walled City of Lahore and in Uch.

In countries, like USA, the local government acts as a bridge between private-sector capital and expertise and publicsector development programs. In developing countries like Pakistan, NGO's or external agencies take over that role, and in case the external agency pulls back, the relations of community and municipality do not survive.

In trying to answer the question about how effective was this approach to urban area conservation and what factors were responsible for the success and failure of the project, it was felt that it was not very successful because it was done as an experiment and the long term commitment was not there, as was seen in the case of OPP. Most of the work 
that had been carried out was on the government owned heritage site. The overall context of economic decline of the city was also a reason for the failure of the project, because investment could not be attracted.

Because of the neglect faced by the residents on the hands of the government they were ready for voluntary and financial contributions to improve their environment related to sanitation and waste disposal, but they did not care much about conservation issues. The priority of people was access to basic needs. As many of the listed buildings were inhabited there was a need to review the whole process of listing the buildings along with the terms and conditions and possibilities of incentive based approach.

The project design for urban area conservation needed to address the following questions clearly in order to be successful.

1. For whom is the conservation being done for the who is supervising the project?

2. What are the hinderances in accessing the local context?

3. What business model has been developed for promoting the economy for people and for investors?

\section{Case Study 2: The Walled City of Lahore}

Lahore is a historical city, dating back to about a thousand years. It has several monuments and sites including globally recognized built form such as the Lahore Fort and the Badshahi Mosque complex. Within the walled city of Lahore one still finds hundreds of heritage buildings, noticeable for their deterioration and lack of maintenance and care. The historic landscape of Lahore, has many aspects associated with intangible heritage, for which Lahore is famous. The project of conservation of Walled City of Lahore started with a cosmetic intervention with the intention of conserving one main bazar of the Walled City, which is supposed to be the historic royal route which the Mughal monarchs used to take from Delhi Gate to their palace in the Lahore Fort. A part of World Bank loan, called the Punjab Municipal Infrastructure Improvement Loan, was utilized for this task. A project management unit was established for this purpose by the Punjab Government and an agreement was signed with the Aga Khan Trust for Culture (AKTC). AKTC in the planning preparation and the execution of the project. A strategic and integrated infrastructure development plan was formulated, which identified a local development framework. Efforts were also made towards developing new legislative initiatives. Under this new legislative framework a master plan for conservation and development had to be prepared (Khan, 2011) (Figure 2).

The pilot project area included the main bazaar, two major monuments, the Wazir Khan and Sonehri Masjid and the adjoining residential neighborhood. The following were outlined for the project:

\section{A question about the stake holders}

2. The role of agencies involved with the rehabilitation and transformation processes.

3. The role of the historical heritage itself in the contemporary urban atmosphere.

4. The question of human development in the light of cultural intellectual and economic development, with the issues of communal identity, self esteem and a sense of attachment to a place.

According to a press report "a project to save the architectural and cultural heritage of Lahore's fabled old city is foundering due to political instability and corruption. Officials say that the World Bank had offered US\$10 million (Dh36.7m) to restore the 2.6-sq-km Old City, home to 145,000 of Lahore's eight million population, but the so-called Walled City project has become mired in bureaucracy and inertia. Jewels of Mughul architecture have been neglected or poorly restored. Havelis, courtyard houses, have been left to rot. Manthe city's decorously carved wooden balconies, or jharokhas (wooden balconies), have collapsed and the streets are squalid." (Rumi, 2008). The report may be exaggerating the situation an ground but one may imagine the problems highlighted in this report, the problem of corruption, substandard work the lack of ownership by the community and the municipality, which may be because of external

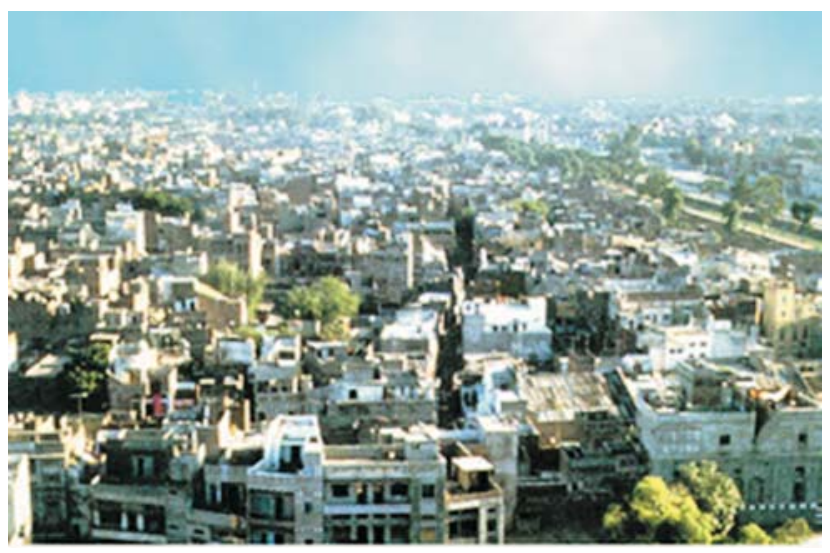

Figure-2: A view of the walled city of Lahore. Source: Rumi, 2008 
funding and irrational decisions for allocation of funds. So the question about the importance of community ownership and the role of external agency arises.

\section{Case study 3: The Saidpur Model Village}

Saidpur is a five hundted years old Pakistani village built on the slopes of the Margala Hills which overlooks Islamabad (figure 3). Saidpur is named after Said Khan, one of the sons of Sultan Sarang, the Gaklhan chief of the Potohar Region .The village was converted into a place of Hindu worship by Mughal commander, Raja Man Singh. The region is home to many Hindu temples that are preserved and show the history of Hindu civilization and architecture in the region (Khan, 2011a).

The Capital Development Authority (CDA) Islamabad converted Saidpur village (housing historic buildings and known for its unglazed pottery craftsmanship) into a model village for tourists in 2005 . The main aim of the project was to conserve the culture of the village and turn it into a tourist spot. The salient features of Saidpur village today are the redesigned restaurants and the three buildings standing closely together, a mundir (a Hindu temple), a church and a gurdwara (a Sikh temple). The CDA, also setup a picture gallery inside the church, with pictures of the village's history.

A sustainable development framework for the development of Saidpur Model Village was not developed or followed for the project. The negative outcomes of the project were eviction of local persons, lack of local people's control over environment, destruction of original architectural integrity of the historic buildings and unauthentic imagery and decoration, resulting in subsequent cultural erosion of the traditional values in the area. The benefits of the project however were, the increase in the number of tourist visiting

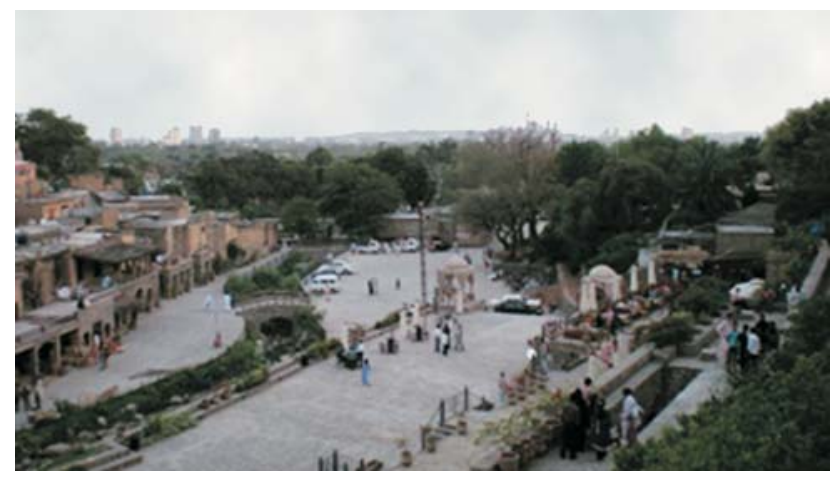

Figure-3: Image of Saidpur village. Source: Khan, 2011a the area, infrastructure developments, adaptive reuse of the dharamshala and the development of a museum for the city of Islamabad. In the process of the development of the Saidpur Model Village, the village was cleaned up and limited opportunities of employment were created for local craftsmen resulting in income generation for local shops (Khan, 2011a: 160-161).

The approach of the development of the Saidupur Model Village was different from the above two approaches and more in line with the market economy. The critiques on physical conservation methodology can be easily resolved by involving experts. Other critiques on the impacts of social and cultural values however need to be addressed.

\section{ANALYSIS AND DISCUSSION}

In Pakistan most people interested in conservation of urban fabric from are academia and they lack resources to work on large scale urban projects. Local people are economically deprived amd do not care about urban conservation. Elite are also not interested either. They have other priorities, so conservation becomes kind of a welfare activity, but in thea age of market economy welfare is not a priority either for the government or for the people unless conservation helps the economy.

Looking at the above three examples of area conservation in Pakistan one can try to understand the problems related to heritage conservation and try to get some direction towards future policy and action. The first lesson that can be drawn is that area conservation especially urban area conservation is not an issue of restricted area only, it is linked to the structure of the whole city and it has to be seen as such. Rationalization of access, infrastructure and land use are important aspects of the conservation of a physical urban context, involving heritage and scenic environment. A good project design should address social and economic issues and outcomes address the community component and aspects of ownership of the project.

The second lesson that can be drawn about urban conservation is about the role of various agencies in the process, i.e. the municipal agency, the external agency and their interaction with the community. In western countries, like USA, municipal agency brings the community and private sector on one ground, but in Pakistan the external agency, like Aga Khan Trust for Culture or OPP brings the municipality and the community on one ground. The disadvantage of this approach is that if the external agency is of permanent nature, like OPP, a trust factor is established 
and things can work out better, but if the induction of external agency is for a short period of time things go in stagnation after the agency exits. Aga Khan Trust for Culture worked for fifteen years in Karimabad to achieve some of the conservation tasks and? OPP has been working since 1980 for community mobilization. Thus, establishment of institutional set up is required on a permanent basis.

The cost and resources required in doing such research, negotiating with partners, arranging finance to put policies in action under the economic conditions and area conservation, becomes a mammoth task. Thus, local mechanisms for funding needs to be established.

The lack of awareness to understand the importance of heritage in communities living in a built environment which is dominated by heritage is evident from the above studies. This awareness has to be inculcated in communities, and civil society has to play a role in creating this awareness.

Many countries internationally have linked heritage with the development of tourism, and thus made urban area conservation economically feasible. In Pakistan the prevailing law and order situation hinders the development of tourism. Furthermore, Pakistani cities lack basic urban infrastructure, thus do not attract foreign investment. As development of tourism needs a mindset of tolerance and respect for other cultures, thus it is important to educate the masses, because unless a tolerant environment is created physical artifacts don't matter.

The gaps in governmental approach towards sustainable heritage area development are also evident in the case of Saidpur village in the form of in its gentrification and lack of follow up after the completion of project. However, the government is becoming more and more sensitive towards heritage issues, and trying to mobilize more funds and resources towards heritage conservation, as is evident in the governments interest in preserving the Makli Necropolis and other archeological sites in Pakistan

\section{CONCLUSION}

From the case studies it can be concluded that the component of culture and heritage are very important in the development of cities, but they cannot be separated from overall planning of economy, education, health and social amenities for the community and the country at large.

Some conclusions that can be drawn for are:

- Pakistan lacks permanent institutional setups and the partnership with government agencies therefore not many conservation exercises are seen in the country. - Although the government has taken some steps to address conservation community based conservation is not on the government's agenda and there is no legislation or institutional work in that direction.

- Generally there is no interest of the community in conservation of heritage, as is evident in the case studies.

- Pakistan lacks development of local funding mechanism to create ownership and stakes of communities. - Funding possibilities are limited for conservation of heritage, although an Endowment Fund has been formed by the government, but that is not sufficient.

- The elite need to be made aware of conservation of heritage and they need to be bought into the main stream of conservation by viewing it as a welfare activity. - Conservation activities need to be linked to infrastructure, economy and social sector. It can be seen that the above described cases have focused on some of these agendas, but with limited success. The living heritage can flourish if its conservation is done on an incentive base rather than on listed heritage base.

- Academicians have promoted many of these values but they have to reach out to the public in general, and the cite in particular to generate results.

- Business models need to involve local businessmen in the conservation projects.

- Terms and conditions for list of living heritage buildings should be modified according to the needs of the local people.

Area Heritage in Pakistan is in a stage of development and more types of approaches need to be tried and tested to reach some conclusions towards the most appropriate approach to area conservation within its context. 


\section{REFERENCES}

Hasan, 2010, "Migration small towns and social transformations in Pakistan", Environment and Urbanization, International Institute for Environment and Development, Vol 22(1): 33-50.

International Council of Monuments and sites, 1964, 'International charter for the conservation and restoration of monuments and sites. (The venice charter 1964), viewed 11 September 2016, form www.icomos.org/charters.

Khan M., 1999, "Forging new alliances to create a sustainable future for the past: Community driven conservation of historic urban and rural settlements in Pakistan", ICOMOS, International Symposium of Culture, Environment and Heritage, Washington DC, USA.

Khan M., 2011, "The future of people and their heritage in the residential quarters of the Lahore Walled City", Sixth Seminar on Urban and Regional Planning, Seminar Proceedings, NED University of Engineering and Technology, Karachi, 43-55.

Khan, S. M., 2011a, "Revitalizing historic areas; Lessons from the renovation of Saidpur village, Islamabad", Sixth Seminar on Urban and Regional Planning, Seminar Proceedings, NED University of Engineering and Technology, Karachi, 150162.

Laiq, W., Soomro, T. A., 2011, “Background Initiatives for Area Conservation in Pakistan”, Seminar on Urban and Regional Planning, Seminar Proceedings, NED University of Engineering and Technology, Karachi.

Rumi, R., 2008, “Shahi Guzargah”, viewed 10 September 2016, from http://lahorenama.wardpress.com/2008/07/01/the royal passage. 